\title{
Achievement Ideology and Alienation in School: \\ Precarious Worth, Impossible Dreams, and Living Another's Life
}

\begin{abstract}
:
Drawing on over two years of the first author's ethnographic fieldwork in two suburban high schools, the authors show how alienation is inextricably linked to an achievement ideology common in many forms of American schooling. In contrast to previous work that either no longer studies alienation or emphasizes alienation as a cause or result of student' lack of achievement, the authors develop a theoretical defense of alienation to show how achieving students can still feel alienated. They describe three forms of alienation using the first author's fieldwork: precarious worth, impossible dreams, and living another's life. They close with the research's political and sociological implications, especially the relationship between the achievement ideology and the study of schools itself.
\end{abstract}

\section{INTRODUCTION}

The relationship between alienation and education has long been of interest to sociologists and other scholars of education. While it is making a small comeback in sociology (Skotnicki and Nielsen 2021), the word "alienation" has generally fallen out of favor in recent decades. Nonetheless, even if they do not use the word alienation to describe their findings, sociologists of education have shown that students who struggle academically often find school to be an alienating experience, with students themselves describing school using terms similar to alienation (Carter 2003; Carter 2005; Howard 2008; Howard 2013; Lewis 2003, Noguera 2009, 
Warikoo and Carter 2009). Other education scholars do cite the concept of alienation explicitly, arguing that schools must become less alienating so that students can achieve at higher levels (Conchas 2006; Conchas and Vigil 2012; Carter and Welner 2013; Hascher and Hagenauer 2010; Taines 2012; Rios 2011, 2017; Stanton-Salazar 2011).

These scholars often take for granted that alienation is either an explanation or the result of a lack of achievement in schools, even generally high-achieving schools (Demerath 2009: 152-184). As summarized in a systemic review of research on school alienation, Hascher and Hadjar (2018) take for granted what we are describing here; they suggest that "bridging the school alienation concept with other notions that are currently emphasized, such as disengagement, helps to improve conceptual foundations and empirical research on educational attainment and the prevention of educational failure" (2018: 173). They argue that alienation is "somewhat neglected in the current discussion of school failure," and that the concept could provide important understandings of "oppositional, disruptive, and irregular behavior" and the relative prevalence of school drop-outs (2018: 173; see also Morinaj and Hadjar 2019; Mau 1992; Newman 1981; Taines 2012; Willis 1977).

In contrast, we draw on over two years of the first author's ethnographic fieldwork to show how alienation is inextricably linked to an achievement ideology common in many forms of American schooling. By studying two disparate schools in "Valley View," an affluent suburb just south of Los Angeles, we are able to focus on the process of achievement for students at multiple levels - from those whose goal is to graduate on time from high school to those striving to matriculate at a prestigious college or university. We show how students who are achieving at each of these levels can often still feel alienated. Moreover, our findings suggest ways in which this alienation stems not necessarily from of a lack of support or encouragement (Taines 2012), 
but rather because of the disconnect between an exacting ideology of achievement in the school district and the students' own experiences and aspirations.

In what follows, we outline our theoretical contributions by reviewing previous work on alienation and describing what we are calling the achievement ideology. We then draw on Author One's ethnographic research, outlining his methodology and then describing three forms of alienation: precarious worth, impossible dreams, and living another's life. We close with the research's political and sociological implications.

\section{THEORETICAL CONSIDERATIONS}

\section{The Sociological Rediscovery of Alienation}

Alienation has been an important problem in philosophy at least as far back as Rosseau and Hegel (Schact 1970) and it gained special importance in sociology (TenHouten 2017) as inspired by Marx's early writings on the various forms of alienation (Dean 1961; Seeman 1959; Erikson 1986, Sciulli 1984, Luke 1967, Fischer 1973) and to the extent that Durkheim's theory of anomie (2006) is itself a theory of alienation (Acevedo 2005, Lukes 1967, Abrutyn and Mueller 2014). Yet the word alienation has fallen out of favor in the past 30 years, due in part to a post-structuralist critique of the underlying ontology of Marxist critique (Lukes 2011). These critics argued that calling a person alienated necessarily assumes a fundamental human psychology and a fundamental social order from which one could be alienated (Yuill 2011; Rosa 2019). These strong ontological claims became both unfashionable and, many would argue, empirically untenable (Jaeggi 2014).

However, recent recoveries of the concept of alienation push against these critiques. The German critical theorists Hartmut Rosa (2019) and Rahel Jaeggi (2014) do not describe 
alienation as a problem of what Marxists would call reification (Honneth 2008), that is an incapacity to recognize the created (and therefore artificial) nature of social things. Instead, Rosa and Jaeggi follow other German-speaking social theorists - most famously Peter Berger (Berger and Luckmann 1967) — in insisting that reification itself need not have an alienating effect as reification is simply the result of any human living in a socially constructed world. Every artifact, institution, and identity is built and maintained through ultimately arbitrary meanings.

For example, simply because the importance and role of schools are social constructions does not mean that schools are necessarily alienating impositions maintained by what Pierre Bourdieu would call "symbolic violence" $(1991,1998)$. It is, of course, certainly true that school only has the meaning and power it does because of people's socialization into a social system (Guhin, Calarco and Miller-Idriss 2021), alongside powerful state, economic, and cultural interests that maintain schools in their current forms and with their current stakes (Gellner 2008, Steffes 2011, Weber 1976). It is also true that schools are maintained by various powers (including teachers, parents, and the state), and that schools are in almost every sense arbitrary: there is no necessary reason for students to go to school, for schools to have the stakes, forms, and meanings they have accumulated, or for schools to teach what they do (Baker 2020, Kliebard 2004).

Nonetheless, many people can experience school - this reification, this arbitrarily created and socially imposed social thing — as simply a part of their life, one which causes no real strain and might well bring a certain resonant (Rosa 2019) sense of meaning and joy (hooks 2003; Ladson-Billings 1995). Of course, there are many students who find school alienating and disempowering, a place of cruelty and imposition more than anything else (Love 2019). Indeed, delineating these experiences is one goal of this article. 
Our point is that even if school is a reification, it is not necessarily the case that school is alienating. Alienation is less tethered to reification by following a key insight in phenomenology: virtually all of social life is an alien imposition, maintained and put upon us by those with more power (Guhin, Calarco, and Idriss 2021). We are all "thrown into" social life as it is already happening, as Heidegger (2010; see also Withy 2011) describes it. By the time we are old enough to be reflective about what elements of life we want to keep and what elements of life we would like to change, we are generally already socialized enough that key elements of our lives feel natural, normal, and not anything we would like to change. While Bourdieu's concept of doxa (2000) brilliantly captures how people turn the arbitrary into a sense of the everyday, his emphasis on symbolic violence in the formation of any social world maintains a "hermeneutic of suspicion" (Ricoeur 2008) whose normative and ultimately descriptive underpinnings we do not share here. Like Berger and Luckmann (1967), we posit that just about anything social is a reification, but whether or not such reification is alienating remains an empirical question. Rosa, following Berger and others, uses this insight to unsettle old Marxian understandings of alienation. Rather than describing alienation via its arbitrariness and imposition, he follows Jaeggi in defining it is as a "relation of relationlessness," contrasting a feeling of alienation with a feeling of resonance, a sense that the elements of a life are related in a meaningful way, creating a co-constitutive, music-like experience of individual and social life. Rosa provides a more thorough definition of alienation as "a situation in which the subject experiences his or her own body or feelings, material and natural environment, or social interactions as external, unconnected, non-responsive, in a word: mute" (Rosa 178-179). This muteness is therefore the opposite of the musical possibilities of resonance: the world feels unavailable or stuck, dead and trapped in the Marxian sense of reification. 


\section{Alienation in High Achieving Students as a Sociological Problem}

Rosa's analysis of alienation has important implications for the study of schooling, implications which Rosa partially explores in his own work (2019: 238-248; see also Felski 2020). As with other scholars of alienation in schools, Rosa seems unaware that achievement might come with its own form of alienation, at least as studied in schools (he is quite aware of this possibility elsewhere). What if even successful students are alienated via an unceasing achievement ideology? Such an argument is a middle way between two theoretical extremes. The first extreme, following work in the Marxian and radical educational traditions, argues that "all pedagogic action is, objectively, symbolic violence insofar as it is the imposition of a cultural arbitrary by an arbitrary power," as such, all schooling, via its inevitably coercive form, is necessarily alienating (Bourdieu and Passeron 2000: 5; see also Bowles and Gintis 2011; for immanent critiques, see Au and Apple 2009; Giroux 1983). Yet if all education is alienating, then describing alienation in schools loses any analytical leverage.

If the first extreme makes alienation in schools so common as to be analytically unhelpful, the second extreme centers alienation not as a problem in itself but as an explanation of other things. In other words, for many scholars, alienation is only important in as much as it is correlated with (and could be said to cause or perhaps be caused by) poor school performance. In this sense, not all students are alienated, and the term maintains analytical leverage. Yet the question of student alienation tends to become a question of student achievement rather than of student experience. Of course, this is not necessarily the case: there are many surveys and studies of school climate that are interested in student flourishing as concerns in and of themselves. Yet, 
especially given how the study of education in the United States has shifted in the past 50 years towards the analysis of socio-economic status, achievement benchmarks, and human capital accumulation (Mehta and Davies 2018; Guhin 2021), the problem of alienation becomes a problem of achievement, or else "achievement gaps" (Ladson-Billings 2006; Carter and Welner 2013). To the extent alienation (or something like it) is a variable in quantitative studies in the economics and sociology of education, it is rarely the dependent variable in question but rather the independent variable explaining differences in achievement and outcomes.

In this paper, we describe three forms of alienation, building on recent work on alienation by Rahel Jaeggi. In so doing, we are sensitive to the other major criticism of previous work on alienation: too often, alienations' meaning is vague and overly diffuse (Seeman 1959, Kohn 1976, Aberbach 1969). To better clarify what we mean by alienation, we develop Jaeggi's pragmatic insight that any "self-conception has a dual character: it is at once an interpretation and a project - a self-interpretation as well as a projecting of oneself" (2014: 125). This distinction between one's sense of one's self and the projected future of that self (Tavory and Eliasoph 2013, Mische 2014) echoes the work of G.H. Mead (2002), and in the three examples of alienation we provide here, the source of alienation is a "relation of relationlessness" between that interpretation and that project. In other words, students are aware of some kind of disjuncture between (1) their own sense of what they enjoy and find resonant and (2) the future towards which they sense they are moving or where others tell them they are headed. Skotnicki and Nielsen similarly define alienation as "futurelessness," treating "alienation as a systemic product [by] explor[ing] how frustrated relationships to the future may speak to compulsory growth, commodification, and other tendencies associated with capitalist accumulation" (2021: 859). While our project is less centered on capitalism itself, we develop a similar description of a 
"frustrated relationship to the future" in our three cases. Students with "precarious worth" sense their very capacity to move forward through time as under threat, making the ability to maintain projects continually precarious. Student with "impossible dreams," sense their goals for the future as either deemed unworthy or rendered unattainable. Finally, students "living someone else's life," sense their very projects as not their own.

\section{Achievement Ideology}

The forms of alienation we describe here are connected to what we're calling the achievement ideology. At its simplest, the achievement ideology is the interlinked beliefs and propositions that both success and personal worth are necessarily related to certain key markers of achievements (e.g. school graduations, employment, marriage). The achievement ideology centers achievements as the key metrics of a life's worth, often also explaining personal or societal problems as problems of achievement or lack thereof.

Scholars have convincingly shown how brutal the need for achievement can be in the United States and other countries, even for already high-achieving students (Dhingra 2020, Lampert 2012), as well as how the language of character education has shifted over time from one of religiously-informed virtue to achievement-oriented grit (Handsman 2021). That need for achievement is partially rooted in America's deep inequality, making a college degree or other metrics of educational success increasingly necessary for any kind of middle-class life, despite vast pressures of debt and time (Labaree 2012, Zaloom 2013). Yet such inequality could be addressed in a variety of ways; that educational achievement is so often suggested as the silver bullet to inequality reveals, we and other suggest, an ideological commitment to achievement and meritocracy (Sandel 2020, Downey 2020, Steffes 2011). 
We use the word ideology not necessarily to mean a belief system that is incorrect, whether empirically or ethically, but rather a belief system which is simplistic, positing straightforward and somewhat predictable explanations for various social problems. We agree with Swidler that an ideology is an "articulated, self-conscious belief and ritual system, aspiring to offer a unified answer to problems of social action" (2002: 96), though we differ from Swidler in that we do not believe such an ideology necessarily entails a closed or sectarian community (2002: 97).

As such, our use of ideology has much in common with what others might call hegemony (Comaroff and Comaroff 2008), yet we continue with the word ideology because what we are calling the "achievement ideology" is important precisely for its relative coherence and its explicit nature, all of which people use to explain and understand individual and collective problems. In other words, the commitment to achievement we describe here is an ideology inasmuch as it is both a relatively confined set of declarative claims about the world (e.g. "those who work hard will succeed") as well as a straightforward and generalized explanation of problems (namely societal inequality and an individual lack of success).

\section{Meritocracy}

Achievement ideology only makes sense within the context of a meritocracy. Many members of democratic, capitalist societies pride themselves on living in meritocracies (Newman, Johnston, and Lown 2015), but it is worth remembering that Michael Young invented the term in what was essentially a sociological dystopia (2017). Young's book foresaw what many scholars of meritocracy now describe: that meritocracy serves as its own justification, developing an ideology of achievement that proves (or so its winners claim) that the best people get the best jobs, thereby meriting the best lives (McNamee and Miller 2009; Sandel 2020; 
Warikoo 2016). It might be impolite to say the reverse must be true as well, that the worst jobs and worst lives wind up filled by the worst people, but so the logic goes (Lampert 2012).

There are subtler versions of meritocracy of course, and more progressive versions of democratic politics generally fall along these lines: we should provide certain social protections to everyone, but the point is not ensuring equality of outcome but rather equality of opportunity (Dobbin 2009; Castilla and Benard 2010), even if what "equal opportunity" means is unclear (Lazenby 2016). This emphasis on equality of opportunity means that schools have become central locations through which to "solve" social inequality, "educationalizing" (Labaree 2009) inequality into a problem of school achievement rather than the unequal distribution of resources.

What is often left unsaid here is that if students will be given a chance to prove themselves through achievement, then other students will be given a chance to reveal themselves through a lack thereof. By insisting on academic achievement as a means of proving worth (or merit), reformers might accidentally be confirming the reverse as well: that a lack of academic achievement proves a lack of worth. Such an ideology can therefore lead to alienation in the senses we have described above, as people come to realize their futures will be marked either by a lack of achievement or by achievements that feel alien and imposed.

\section{DATA AND METHODS}

\section{Research Sites}

There are six public high schools in Valley View, the Los Angeles suburb where Author One conducted his fieldwork. Of these, "Pinnacle High School," our first field site, is the flagship high school in the district and consistently ranks as one of the top schools in the state. "Crossroads High School," our second field site, is the district's continuation school - a place 
where students are sent when they have fallen behind on their course credits such that they are no longer on pace to graduate with their class.

\section{Data Collection}

Author One's methods of data collection included over 400 hours of observation and 122 in-depth interviews with a variety of institutional actors at both schools. Author One made repeated observations in multiple spaces and events, including classrooms, assemblies, faculty meetings, back-to-school nights, and awards ceremonies (e.g., trophy presentations and graduations). Observing in a wide variety of school settings allows the ethnographer to minimize the extent to which important aspects of the settings and situations under study are inadvertently excluded from the analysis (Duneier 2011). Author One was often able to take copious field notes, by hand in a notebook, within these spaces on both school campus. He supplemented his notes with analytic memos to provide a "running record of [his] early analytic musings and proto-conceptions" (Lofland et al., 2006). He also engaged in dozens of informal conversations with teachers, administrators, students, and parents in accordance with the "interviewing by comment" technique of qualitative data gathering (Snow et al. 1982).

The first six months of field work were strictly observational with no formal interviews, a period during which Author One gradually built rapport with various institutional actors. As such, by the time he started conducting interviews, he had established a level of familiarity and trust that allowed him to have candid conversations with various members of each school community, and to develop a better knowledge of the schools' meso-level cultures (Rinaldo and Guhin 2019). To obtain student interview subjects, he introduced himself to each class in which he was observing and passed around a signup sheet for students to indicate their interest. He 
secured additional interviews with students, teachers, staff, and parents via snowball sampling (Biernacki \& Waldorf 1981).

At Crossroads, Author One interviewed 59 students (30 girls and 29 boys), 9 teachers, 3 administrators, and 6 parents, and he participated in a focus group discussion with 12 additional parents. At Pinnacle, he interviewed 28 students (15 girls and 13 boys), 7 teachers, 4

administrators, and 6 parents. ${ }^{3}$ Author One asked all students to identify their race as part of the interview, and the results of that inquiry are presented below in Table 1.

\section{[TABLE 1 HERE]}

The number of each racial group in the Crossroads student sample roughly corresponds to the percentage of each racial group in the entire student body at Crossroads. In the Pinnacle student sample, Black and Latinx students are overrepresented as compared to their percentages of the entire the student body because Black and Latinx students were overrepresented among those who transferred to Crossroads.

The interviews ranged in length from 24 to 67 minutes, with a mean length of 39 minutes. Author One conducted all student interviews on either the Pinnacle or Crossroads campus during weekdays on which classes were in session. He interviewed students during the lunch period, during class periods (with teacher approval), or on campus after school. He conducted all interviews with teachers during free periods or after school, typically in their classroom. He obtained consent to audio-record each interview, and each recording was transcribed verbatim, either by him or by an undergraduate research assistant whom he trained. 


\section{TWO DISPARATE HIGH SCHOOLS IN AN AFFLUENT SUBURB}

Valley View is an affluent suburban community. In 2020, the median household income was well over $\$ 100,000$ and $66 \%$ of adult residents had earned a Bachelor's Degree or higher. ${ }^{2}$ Valley View's 2020 population of nearly 300,000 residents represents an increase of more 30\% since 2010, and the ethnoracial composition of the city reflects broader contemporary immigration flows in middle-class California cities: Valley View is predominantly Asian (44\%) and White $(41 \%)$, but also has a sizeable Latinx population (9\%) and a small Black population $(2 \%)$.

Pinnacle High School is the flagship high school in the city, and consistently ranks as one of the top public high schools in the nation. Ninety-six percent of Pinnacle's graduates enroll in post-secondary institutions, and roughly $70 \%$ enroll in four-year colleges and universities. The Ivy League and University of California system are popular among Pinnacle's college-goers. The school's academic profile grows more impressive when one considers that Pinnacle enrolls nearly 2,500 students each year, with class sizes routinely approaching forty students.

Pinnacle sits on a sprawling fifty-five-acre campus, with meticulously manicured greenery and impressive school structures that rise above dozens of neatly pruned trees. Pinnacle boasts a theatre/auditorium, gymnasium, baseball field, football field, all-weather track, swimming pool, several tennis courts, and separate buildings to house its math, science, humanities, arts, and athletic departments. The curriculum offers twenty-nine honors and advanced placement courses, dozens of sports, clubs, and student government opportunities, and a robust peer tutoring program. Pinnacle is an open campus with no walls or fences to separate the school from the surrounding neighborhood. Students are permitted to leave campus during lunch period or a free period, and they often do so as a way to socialize with friends. 
Crossroads High School provides none of these features and opportunities for its student body, which typically swells throughout the school year from around 150 to 220 as small groups of students are transferred in multiple waves. At back-to-school night during the fall of Author One's second year of field work, the school was selling t-shirts that read, "Crossroads Athletics: Undefeated Since 1974.” The shirts were intended to be humorous because Crossroads has no sports teams. In fact, they have no drama program, no music program, no student clubs, and no parent-teacher association (PTA).

Crossroads also lacks material academic resources: the school has no library, a shortage of textbooks such that students are not able to bring textbooks home with them from school, and a curriculum limited to include only the classes necessary to earn a high school diploma in California. The truncated curriculum is especially consequential. Regardless of their academic record at Crossroads, even if they earn straight A's there, graduates who pursue postsecondary education are ineligible to enroll in a four-year college or university and must instead choose a community college or trade school. This is significant given that less than $30 \%$ of students seeking degrees at California's community colleges either attain them or transfer to four-year universities within six years, and over $80 \%$ of California community college students who do not graduate within six years drop out of college altogether (Moore \& Shulock 2010). Students can return from Crossroads to their neighborhood high school once they have recovered enough credits, but return is rare. For example, from 2014 to 2016 - when the majority of our data were collected - only $17 \%$ of Crossroads students who were eligible to transfer back at the end of the school year did so.

Pinnacle and Crossroads also differ starkly in the racial composition of their student populations, particularly in terms of students of color. As Table 2 shows, while Asians comprise 
$44 \%$ of Valley View's population, they constitute $52.2 \%$ of the student body at Pinnacle and only 9.5\% at Crossroads. Black and Latinx students are grossly overrepresented at Crossroads: they comprise $2 \%$ and $9 \%$ of Valley View's population, $2.4 \%$ and $7.1 \%$ of Pinnacle's student body, but $9.4 \%$ and $36.5 \%$ of the student body at Crossroads, respectively.

\section{[TABLE 2 HERE]}

These disparities illustrate the extent to which the Valley View Unified School District's continuation school model disproportionately affects Black and Latinx students.

The arrangement between Crossroads and the district's four mainstream high schools stipulates that students are transferred to Crossroads because of academic underperformance, not behavioral problems. Nevertheless, and though the school is nestled well within the boundaries of an affluent suburb, the physical space has multiple features that are common to schools in neighborhoods plagued by violence and illicit activity: the grass beside the school is uncut and growing wildly; the school's administration and classroom buildings are rectangular with low ceilings and flat roofs such that they resemble a series of trailers; an imposing, seven-foot metal fence runs around the school perimeter (Crossroads is the only high school in the district with a perimeter fence); floodlights dot the courtyard; a squad car from the Valley View Police Department is always parked at the curb just in front of the main entrance; a Valley View police officer, armed with a yellow taser and a pistol, is a conspicuous presence on campus during arrival, passing periods, lunch period, and dismissal. The fence, campus buildings, and interior courtyard are configured for the panoptic surveillance of students. The classroom buildings and main office comprise three sides of a rectangle that insures that students are always visible when they are outside of a classroom or the main office. The only openings in the fence are at two gates that are closed and locked at all times except during arrival and dismissal. 
During one of Author One's early morning visits to Crossroads, he stood with Mr.

Johnson, the school principal, and Officer Williams, the Valley View police officer assigned to Crossroads, on the blacktop just outside of the main office. They were making small talk and observing students arriving for first period classes. During the course of their brief conversation, Author One made a comment about the uniqueness of the fence at Crossroads. Mr. Johnson responded with a pointed criticism of the campus layout and the school's general orientation toward students:

\section{AUTHOR ONE: I think Crossroads is the only high school in Valley View with a perimeter fence like this.}

MR. JOHNSON: That's right. The district built this school according to a prison model, which is unfortunate. Quite frankly, I don't think it's appropriate as a high school setting. In fact, I'd love to take that damn fence down...It sends a message that these are bad kids and, unfortunately, our students sometimes internalize that message.

Indeed, the campus layout was a constant point of contention and for Crossroads students, who frequently questioned the need for such a punitive posture. Rinna, a 16-year-old Filipina sophomore, was one such student:

RINNA: The cop is here and he's armed with a pistol and always watching us, and it shows that they don't have trust in us. And, on top of that, we're fenced in all day, so this school is like a prison or a jail. It makes us feel like we're bad kids or something, but we're not.

The constant presence of police and the perimeter fence are particularly unflattering distinctions that render the space as fundamentally disciplinary to students.

To be sure, many schools, in a variety of neighborhoods, sit on grounds delineated by fences, bars, and locked gates. Many schools have a visible presence of police and other security officers. However, these elements of the Crossroads campus are especially troubling for students 
when considered within the broader context of Valley View's high schools. Pinnacle High School, like all comprehensive high schools in the district, is an "open campus." As such, there are no fences or gates around the campus perimeter, and students can enter the school from multiple sides. Pinnacle students are free to leave campus during lunchtime and free periods. During the lunch period, one can often see a stream of dozens of Pinnacle students walking in small groups down one of the main streets near campus toward an upscale strip mall that contains several popular eateries and a large grocery store. Crossroads students do not have the privilege of leaving school during the lunch period. Instead, they are confined to an outdoor courtyard where they can receive lunch or a small snack from a kiosk, all while being closely watched by an armed, uniformed police officer. In sum, while Pinnacle students enjoy a wealth of academic resources, extra-curricular opportunities, and spatial freedom, Crossroads students' high school experience is one of relative deprivation and disadvantage.

Achievement takes on different meanings across our two field sites. At Pinnacle, a narrow, exacting definition of success fosters an academic culture of restless striving and competition that alienates students across all types and levels of academic achievement. Students whose test scores, grades, and goals fall outside the lofty realm of what is considered praiseworthy are particularly susceptible to alienation, yet even the most successful of students can feel as though the schools' definition of achievement is an imposition and hoop through which they have to jump rather than a meaningful part of their lives. Among students who struggle academically at Pinnacle, we focus on those who transfer to Crossroads for "credit recovery." Transferring to and attending Crossroads is a demoralizing and stigmatizing experience for students. Thus, for Crossroads students, district policies and practices dictate that their only viable path to graduation (i.e., to achievement) requires them to endure the stigma 
associated with enrollment at a separate, inferior school. These distinctions all have important implications for the forms of alienation we describe below.

At first, this comparison might seem to be the same sad story told about how inequality leads to alienation, with under-resourced schools leading to unmotivated students. Indeed, these two schools are almost ideal typical examples of the inequality within American education. Yet, as we will show, the experience of alienation is not exclusive to the marginalized school, or even the marginalized students within the successful school.

\section{ALIENATION ONE: PRECARIOUS WORTH}

For many students at Pinnacle High, success was linked to their moral status as people, making the possibility of failure not only frightening in academic terms but also in moral ones, in the sense of their broader self-worth and sense of themselves as good and deserving people. Part of the reason Pinnacle students struggled so much with alienation despite their success was the degree to which the school's "institutional success frame" was so beholden to the ideology of achievement. As Drake (2017) describes it, an institutional success frame is a collective interpretation of academic achievement cultivated and perpetuated by institutional actors. An institutional success frame includes definitions of individual and group success within an organization that are widely acknowledged and understood by members (see also Nunn 2014). Institutional success frames enable individuals to make sense of their circumstances and experiences as institutional actors, and they inspire both individual and collective action. At Pinnacle High School, the success frame holds that students enroll in a challenging series of honors and AP classes, attain at least a 4.0 grade point average (GPA), achieve tops marks on 
standardized tests, participate consistently in extracurricular activities, and gain admission to a prestigious four-year college or university. In short, academic excellence is the expectation.

When linked to an ideology of achievement, as is the case at Pinnacle, an institutional success frame can make it all but impossible to ever really be done: there is always another club to be president of, another AP class to take, another community service opportunity to put on a college application (Dhingra 2021, Demerath 2009). This level of stress and anxiety is related to the fundamental uncertainty of any achiever's status within a meritocracy: until the most prestigious acceptance letter arrives, there is always the possibility of rejection and failure. And most importantly, as described above, this need for a status linked to achievement is not only a function of Bourdieusian field position (1998), but also along the lines of Calvinist predestination, a moral marker of worth (Sandel 2020). As such, and as with Weber's famous study of Calvinism and its "Protestant ethic" (2001: 39), there is continual anxiety that the work might not be enough and that the status as "chosen" might easily be lost. The certainty of one's salvation is as unattainable as the status of one's salvation is inscrutable. Achievers-whether Weber's Calvinists or today's meritocrats-face an unceasing anxiety about not only the future but the future's existential stakes (Purser and Hennigan 2017). For the students Author one worked with, the ideology of achievement might not refer to paradise or damnation after death, but it does refer to a similar kind of binary of life after high school: Will students be failures or successes? Any discrete achievement can give them some answer, but never enough, so they must keep achieving even more. The alienation that emerges from a separation between a projected future and a self-interpretation is rooted in the uncertainty of future success.

That alienation is driven by the ideology of achievement, which is a constant presence on campus. For example, the school's academic prowess is a permanent part of the physical 
architecture. A large brick arch, roughly the width of a single-car garage and the height of a school bus, frames the front entrance to the main office. "PINNACLE HIGH SCHOOL" appears across the top of the arch in large metal letters affixed to the bricks. Two phrases are positioned at eye-level on either side of the arch. The phrase on the left side reads, "California Distinguished School," and the phrase on the right reads, "National Exemplary School". In California, distinguished and exemplary school commendations are bestowed annually and correspond to particular school years. Author One witnessed similar awards on display at other high schools in the county, typically as pennants or banners indicating the specific year or years in which the awards were won. But Pinnacle takes a different approach to displaying these awards by effectively tattooing the accolades to its entranceway as immutable components of institutional culture and identity.

Conspicuous signs and reminders of the ideology of achievement also show up in classrooms. For instance, Mr. Ventura, a freshman and AP biology teacher, teaches in a room with dozens of college pennants lining the upper walls. These pennants represent a selection of the colleges and universities that Mr. Ventura's former students chose to attend. A brief scan of pennants positioned along the back wall reads like a published list of top-ranked post-secondary schools: Harvard, Stanford, Princeton, Yale, Columbia, M.I.T., Cal Tech, UCLA, USC, UC Irvine, UC Berkeley, UC San Diego, UC Santa Barbara, Duke, Brown, Dartmouth, NYU, Georgia Tech, Vanderbilt, Michigan, Northwestern. For Mr. Ventura, the prestigious postsecondary enrollment of his former students is a source of "personal pride," and the pennants serve as badges of pedagogical honor. The display is also indicative of how linked Pinnacle's institutional success frame is to the achievement ideology, - a tacit reminder to current Pinnacle students of the level of success that is expected of them as members of the school community. 
In so doing, Pinnacle students are also disciplined into an understanding of what student worth looks like, thereby learning what worthlessness looks like as well. Indeed, the source of alienation within the ideology of achievement is not so much that it centers achievement: achievement is often quite meaningful for many students; indeed, according to Dewey (1997), something like achievement (what he calls growth) is the source of personal meaning itself. Achievement becomes alienating not when it is emphasized but when it is externalized, when students feel as though certain pre-set achievements are absolutely necessary for a meaningful life and that without them, their capacity to move forward in their own projects are eliminated, or, at best, precarious.

Once they arrive on campus, first-year Pinnacle students rapidly come to understand what it takes to reach this level of achievement and be worthy of praise and accolades. For many, the key is taking as many honors and AP classes as possible. For example, during Author One's second full year of fieldwork, the Pinnacle faculty considered offering an optional "zero period" that would begin around 7:15 a.m. and conclude before the first bell of the regular school day at 8:05 a.m. Many faculty members were concerned that too many students were loading up their schedules with too many honors and AP classes, and they wanted to create a space for students to engage with music, art, and other related fields. They administered a survey to families to get a sense of what "fun" and "creative" subjects students would be interested in taking early in the morning, but the plan hit a snag when the results came in: according to an assistant principal, "The vast majority of families who returned the survey indicated that they wanted additional AP classes during a zero period." The plans were put on hold, and the issue remained unresolved as Author One wrapped up fieldwork roughly six months later. A sense in which there's never enough achievement is maintained by parents as well. 


\section{Shaming Students who Struggle}

The precariousness of achievement—and through achievement, worth— is further reinforced by pedagogical practices that call out students who are struggling and privilege the highest achievers. Ms. King, who teaches freshman algebra, provides a case in point. Once a week or so, after passing back graded exams, she always begins class by opening a spreadsheet on her computer that lists each student's ID number and their cumulative grade in the class. She displays the spreadsheet through an overhead projector and reads down the list, referring to various students by their student identification numbers and commenting aloud on their scores and grade point averages. "22915, you just barely made the cutoff for an A." "22513, you just made the cutoff for a B, but if you slip up you might get a C. You don't want to ever get a C." She now skips down the list to the small handful of students who are nearly failing. " 22398 , do you want to take algebra again next year? Because that's the path that you're on right now." "22887, you are in the wrong class. Your performance so far makes that clear." Ms. King now focuses on the three students who currently have failing grades in the class, using a laser pointer to highlight their scores on the spreadsheet. "These three kids will not survive, plain and simple." she announces. The use of the word "survive" here highlights what teachers and students understand as existential stakes.

It was not clear whether any of the students who Ms. King singled out that day were identifiable to their classmates by their ID numbers. Indeed, Ms. King referred to them by their ID numbers so as not to embarrass them by name, even if some level of public (albeit anonymous) shame was clearly intended. She hoped that comparing their grades in a public fashion would, as she put it, "inspire improvement." And such improvement might well have been inspired, yet along the lines of the achievement ideology we have been describing: success 
at math is framed, at least in this context, not as a creative capacity with numbers or the enjoyment of interesting equations we might solve. Instead, success is a position on a list, linked either to praise or, more commonly, precariousness, with a risk of dropping to grades the right kind of student should never receive (a C, for example) or, more existentially, failing out of the class or even the school.

If Ms. King was hoping to inspire, her tactics backfired, at least with some of those students. A few weeks later, Cindy (White, 15-years-old) - student 22887, who had been told that she was "in the wrong class" - clearly articulated how it felt to be shamed in class because her grades were incompatible with Pinnacle's success frame:

AUTHOR ONE: What's it like to get called out in class like that and compared to
everyone else? CINDY: You already feel like you don't belong because everyone else is doing better, and then on top of that to be straight up told that by a teacher just really sucks. You feel like you don't belong and then your teacher confirms it. Last year, in eighth grade, I thought I was pretty smart, but this year I'm not so sure.

As Cindy's comments make clear, Ms. King's approach did not motivate her to improve; instead, it made her question her intelligence and whether she belonged at Pinnacle. Cindy's experience is emblematic of Pinnacle students whose grades are below the class average. To be below average — indeed, even to be average — is to feel out of place and unwelcome.

Here is the paradox of the achievement ideology: Cindy ended up doing just fine. She passed Ms. King's class with a C. Two years later, in the spring of her junior year, her plan was to attend Cal State Northridge, Cal State Fullerton, or Cal State Long Beach, and she had grades and test scores that positioned her to achieve this goal. Certain ways of doing the sociology of education would look at Cindy's trajectory as one of success: here is a student who did well enough in high school, got a four-year degree, and went on to get a job. Yet such an analysis 
would miss the alienation Cindy experiences along the way, not least because of the stress that she might not be able to move forward with her plans as she had hoped she could, that she might not measure up to her peers and be "worthy" of Pinnacle.

The academic culture at Pinnacle, which is based on the necessity of achievement, is particularly unforgiving for students who fall behind on course credits. Teachers, counselors, and administrators often feel compelled to strongly recommend to such students that they transfer to Crossroads, motivated in part by wanting to keep Pinnacle's own numbers as strong as possible. Mariah, a 16-year-old African American junior at Pinnacle whose grade point average had dipped during sophomore year, felt that counselors and assistant principals pushed her to transfer to Crossroads rather than attempt to help her improve her grades:

MARIAH: Pinnacle is supposed to be a great school, but the teachers don't care about you. They just care about the students that started off good and are the top students. When I struggled, they were trying to find a way to get me out of the school instead of helping me. They just pressured me to go to Crossroads.

Mariah perceived teachers and administrators to be uncaring and indifferent toward her academic struggles. She felt this precariousness of worth we are describing: her worthiness to be treated as someone who deserved care,= was a function not of her status as a person or student but rather her status as an achiever. Her worth was precarious, and its link to achievement caused a sense of alienation that others did not believe in her or see her projected future as worth helping. As a result, Mariah felt detached from the school community. Note also how the alienation is necessarily connected to a future project, or, rather, the avoidance of a future damnation: ending up at Crossroads.

AUTHOR ONE: Do you feel like you're an important member of the community here at Pinnacle?

MARIAH: Um, not really. I go to school here, but honestly that's about it. I don't really fit in here because this school is so competitive and everyone is so crazy on 
grades and stuff. Once I figured that out, I just started keeping to myself even more and I don't do any sports or clubs or anything like that. I did that stuff in middle school but I don't anymore. Basically my focus here now is just making sure I don't end up at Crossroads.

At Pinnacle High School, Crossroads is an institutional emblem of unworthiness, widely believed to be a place for students who are "lazy," "delinquent," or whose parents "don't care about education as much as they should." For example, Ms. Reynolds, a substitute teacher in her mid-twenties who often subs at Pinnacle, told me that despite never having set foot on the Crossroads campus, she refused to teach there because she does not want to be "terrorized by a bunch of bad kids."

Crossroads also has a decidedly negative reputation among Pinnacle's students. During a conversation with Eugene, a 17-year-old Korean - American junior and the son of college professors, and Patrick, a 17-year-old Chinese - American junior whose parents are chemists, they summarized what I found to be the predominant perception of Crossroads held by Pinnacle students:

\section{What do you know about Crossroads High School?}

EUGENE: Crossroads is like the penitentiary for students. If you go to Crossroads, you have failed miserably as a student and a person.

PATRICK: Yeah, Crossroads is the bad school. It's almost like, if you mess up, then you go there, so it's almost like a prison. Because if you mess up here [at Pinnacle], then you go over there, and you're done for life, pretty much.

For students in Valley View, Crossroads is a place to avoid because it is associated with deviant behavior and failure. Note the elements of alienation we have been describing: the existential stakes as described by Eugene, the sense of futurelessness as describe by Patrick. The fears of Crossroads are linked ideologically via the connection between achievement and worth: to go to 
Crossroads means one has not achieved and is incapable of living in the right way; to lack this type of achievement is to lack worth. Students understand the potential long-term academic and career consequences of enrolling at Crossroads, which is evident in Patrick's comment that students who end up at Crossroads are "done for life."

Yet this labeling of Crossroads was not only a problem for students at Crossroads. It created an intense anxiety for students at Pinnacle as well, leading to a sense of alienation for students at risk of "failing miserably" by going to another, lesser school. Students — especially students who were set to transfer to Crossroads from a neighboring high school - expressed feelings of dread at the thought of attending a school with such a frightening reputation. For example, Celia, an 18-year-old senior who emigrated to the United States from Mexico with her parents at the age four, was "terrified" of being transferred to Crossroads:

\section{AUTHOR ONE: What was it like for you when you knew you were coming here [to Crossroads]?}

CELIA: When I found out that I was being transferred I started asking around at Pinnacle and I heard that the kids at Crossroads are all drug addicts, and you might get assaulted in the bathroom, and there is always smoke in the bathroom. I got so terrified I went home and cried. Even the first day here, I came through the office and I didn't wanna come inside because I was so scared. It looked like a place where that stuff might happen, with all the bars and stuff. It didn't look like a school.

The anxiety that Celia felt was typical of other students in our sample who found themselves in the same predicament.

Crossroads students often expressed a great deal of shame and embarrassment simply for being there, reflecting the sense of worthlessness we are describing here. These feelings were frequently echoed by other family members. In a conversation during lunch one day with Juan, a 17-year-old Mexican-American 11th-grader, he told me that his father, a real estate agent, was 
dismayed when he found out that Juan was being transferred to Crossroads. "My dad believed that Crossroads was a school for bad kids who do drugs and make trouble. He felt that me being here would downgrade our family name." Juan told Author One that his father also feared for his real estate business, worrying that if his clients found out that his son was a student at Crossroads, they would not want to do business with him:

JUAN: I usually go with my dad to look at houses with his customers. They'll ask me, "Where do you go to school," and I used to say, "Crossroads," but my dad was like, "Don't tell them that." He thought it would be bad for his business and the family. So now I just say I go to Pinnacle.

These examples are representative of a clear pattern that emerged in our data - the worthlessness of Crossroads High School in the local community, and how the alienation such feelings of worthlessness engendered affected Crossroads students and their families, as well as students at Pinnacle who worried they might wind up at Crossroads. Why was Crossroads so terrifying? Because to go to Crossroads meant to become worthless within Pinnacle's success frame. And that worthlessness meant not only a general shame but also an alienation, a lost relationship between one's interpretation of the self and the projected future upon which that self might embark. As Juan's dad told him, to be at Crossroads meant future customers would avoid them. Celia imagined a future of hiding in fear. Crossroads — or at the least the imagined Crossroadsis not a school in which students can project futures; it is a place only to survive. As with Weber's discussion of Calvinism, early success indicates both later success and the revealed identity of a successful person, while early failure indicates later failure and the revealed identity of a failed person, a person with neither future nor worth.

Inspired by the achievement ideology, students and teachers at Pinnacle had linked certain measures of academic success to student worth, meaning that achievement took on much 
greater stakes than whether or not students understood materials or could avoid summer school. Instead, achievement meant an almost ontological indication of moral worth, a sense that some students are "worthy" of the resources at Pinnacle, and others are not. And those that are not deserve shame, scorn, or ought to lie about it, like Juan was encouraged to do. This fear of meriting shame led to a sense of alienation not only for Pinnacle students who were in real danger of transferring to Crossroads, but even for those who recognized the precariousness of the entire situation. Like Weber's Calvinists, these were people terrified that a sudden change might send them over to the damned.

\section{ALIENATION TWO: IMPOSSIBLE DREAMS}

The district's approach to students who fall behind on credits at comprehensive high schools like Pinnacle is that a transfer to Crossroads is their only viable path to graduation; in other words, there is no path to achievement for them at schools like Pinnacle. For students who are transferred to Crossroads, their most salient achievement goal - the goal they most commonly expressed in casual discussions and formal interviews - is to graduate.

Yet achievement as Crossroad is almost necessarily alienating. At Crossroads, students are given impossible dreams: they are consistently told that the model of a successful student - a worthy student - is one who completes a four-year degree. This is the future they are asked to imagine themselves in, towards which they should direct the projects of their lives. And yet the school's meager resources make such a dream all but impossible for many of its students, even those who do well academically and quickly catch all the way up on credits. The carceral layout of the campus certainly contributes to the marginalization and demoralization that students feel, but the curriculum itself is also a source of disaffection, disappointment, and impossibility. This 
is particularly the case for the highest achievers at Crossroads, some of whom are not made aware of the school's curricular limitations until after they begin the college application process. Consider the experience of Dominique, a Black, seventeen-year-old senior who was set to enroll at Valley View Community College after graduation:

\begin{abstract}
AUTHOR ONE: Why did you decide on [Valley View Community College]?
DOMINIQUE: The decision was pretty much made for me. I went to [the guidance counselor] and told her that I wanted to apply to Long Beach State because my cousin goes there, but she said that my only option for next year was to go to community college. And that was shocking to me because I've been doing really well in all my classes here.
\end{abstract}

AUTHOR ONE: Did she say why?

DOMINIQUE: Yeah, because we can't get all the classes we need here, so I wouldn't even qualify for a state school.

Dominque had a perfect attendance record and passed all of her classes. She was popular among her peers and praised as "hardworking," "focused," and "going places" by her teachers.

Unfortunately, the places she could go after high school were constrained by Crossroads's skeletal curriculum. Dominque realized that her hard work and achievements did not amount to much, at least not as much as she thought they would, leading to a disconnect between her interpretation of herself and the project that self was able to live out.

Dominique is doing what she is supposed to do and will most likely wind-up finishing community college and going on to get a four year degree, yet a combination of achievement ideology and its concomitant resource hoarding has meant that she feels a disconnect from her sense of herself and the future she is able to have. Certain sociological studies of Dominique might still portray this as a story of achievement — especially stories that will only examine her long-term outcomes of (we would predict) eventual college completion—but these studies would 
miss the emptiness of Dominique's achievement, the alienation she feels that she cannot pursue the goals she has been continually told to pursue.

The achievement ideology is a part of this story in two ways. First, because of the continual sense that Dominque must "prove" and "overcome" the lack of worth put upon her by a lack of achievement, manifested in attending Crossroads. Second, and more importantly, the existence of a school like Crossroads is itself evidence of an ideological commitment to center high-achieving students, keeping lower-achieving students separate, literally walled off, and bereft of the resources that might or might not help them succeed (Downey 2020) but which would certainly make their day-to-day experience less marginalized and alienating.

\section{The Achievement Paradox at Crossroads}

Indeed, Dominique's disappointment is indicative of a broader achievement paradox at Crossroads; despite the fact that Crossroads is a continuation school, some of the expectations that Crossroads's teachers and administrators have for students, and the signaling of achievement goals on campus, are similar to what our data from Pinnacle show. Our data reveal recurrent slippage between students' projected futures and the expectations that faculty had for them. At Crossroads, faculty members' expectations of students were often based on a framing of success that somewhat mapped onto the academic culture at Pinnacle. These expectations go something like this: all Crossroads students should strive to graduate having gained admission to a four-year college or university, because attending a four-year college or university is the surest path to a fulfilling and lucrative career. This college-or-bust culture (Rosenbaum 2001) belies the reality on campus that most students were simply hoping to graduate on time and had no intention of ever enrolling at a four-year college or university. Furthermore, for those who do have their 
sights set on continuing their education after high school, college enrollment is often a distant goal, with no clear or reliable path to attaining it (Rios 2017, Cottom 2017).

This alienating mismatch between students' own projected futures and institutional expectations is often glaring. For example, one of the classrooms at Crossroads is also used as a college counseling office and a place to host orientation sessions for new transfers. This room is a space in which students are often thinking about and planning their futures in some way. Three of the room's four walls are covered in colorful pennants representing various four-year colleges and universities, many of them highly ranked and with low acceptance rates for undergraduates. The irony of this display is that Crossroads graduates are ineligible to enroll at any of those schools no matter how well they perform in their classes. Students take note of the contradiction; while seated in the room, some periodically make comments such as, "What's up with these walls? Why are they reminding us about all the great schools we can't get into?!" or, "I think they're straight up trolling us with these college decorations."

Several of the pennants were the same as the ones that Mr. Ventura had posted on the walls of his science classroom at Pinnacle. At Pinnacle, those pennants were a reminder of what could be in store for graduates - of the boundless and exciting possibilities that awaited those who excelled. At Crossroads, those pennants were unintentional symbols of deprivation - a reminder to students of what they could not achieve.

Though our Crossroads data come from hundreds of hours of observation and dozens of interviews and informal conversations on campus, it took only a few weeks of on-campus fieldwork to glean that very few Crossroads students were interested in enrolling at a four-year college or university. Some had such aspirations when they started their freshman year at Pinnacle or another comprehensive high school in the district but had abandoned that objective 
before transferring to Crossroads. Others arrived at Crossroads still eager to eventually attend a four-year college or university only to gradually succumb to a student-body culture of academic apathy that was exacerbated by the school's punitive policies. Still others - the majority of those in our sample - never intended to go to college at all, but this did not mean that they lacked ambition, concrete career goals, or a sense of life as projected into the future. Miguel was one such student, and his case is an example of the frequent distance between students' goals and institutional expectations of students in the district.

\section{The Rejection of Miguel's Achievement}

Miguel, a 17-year-old junior, began his high school career at Pinnacle. He was affable, a good athlete, and popular among his classmates, but he did not enjoy the academic aspects of school. He put very little time into his studies, and his grades reflected his lack of effort. At the end of his sophomore year at Pinnacle, he was summoned to the counseling office and told that he would need to begin sophomore year at Crossroads.

During his orientation at Crossroads the next fall, one of the academic advisors asked Miguel about his plans for the future. He told her that he loved to cook for his family at home and that he wanted to be a chef and open his own restaurant someday. She recommended that he enroll in culinary arts courses though the district's vocational education program, and he did. Miguel excelled in culinary arts. He enjoyed the program because, as he put it, "I get to learn and practice stuff that I'll need when I get a real job. I know I'll never use what we're doing in my other classes, so what's the point? I really don't see the point." Things were looking up for Miguel despite his disinterest in the core curriculum. When he was enrolled in culinary arts, he felt less alienated; to go back to Jaeggi's linking of self-concept and self-project, Miguel was 
able to understand who he was then as necessarily related to the future projects he had planned. But his increased sense of belonging and purpose would not last.

During Mr. Johnson's tenure as principal, particularly in the first year or so, several teachers complained during faculty meetings that too many students were showing up late for first period. (Miguel was one of those students.) In response, Mr. Johnson developed a plan to compel more students to arrive on time for their first period class. He enacted a policy, with district support, that students who were late eight times in a single semester would face a series of penalties, one of which was that they would be pulled from any vocational classes that they were enrolled in. Mr. Johnson justified this approach by arguing that vocational classes were an “extracurricular privilege" and "not a graduation requirement." But for students like Miguel students interested in learning a trade that would help them launch a career - culinary arts and other similar courses were much more than "extracurricular"; they were a lifeline to a meaningful career amidst an otherwise alienating high school experience. No longer in the program, Miguel began skipping school altogether, only showing up occasionally to turn in assignments or when he wanted to see his friends. He eventually dropped out of high school. Given a certain way of understanding worthwhile achievement, Miguel's dream became impossible, at least at school.

Miguel's case is a vivid example of how a narrow, rigid frame of achievement can alienate students who may project futures that do not fit within that frame. At Pinnacle High School, academic achievement was typically defined as earning top marks on grades and test scores in order to gain admission to a renowned four-year college or university. Although Pinnacle was the flagship public high school in the district, the same success frame was prevalent at each of the four other comprehensive public high schools in Valley View, all of which were 
considered academically rigorous institutions. Our data suggest that Crossroads students were sometimes subject to similar definitions of school success, particularly the necessity of a fouryear college degree. This frequently resulted in an alienating mismatch between Crossroads institutional expectations on one hand and students' aspirations and goals - their dreams - on the other. The display of college pennants in the counseling office reminded students of their academic shortcomings and the impossibility of achieving these dreams given where they were. Miguel's expulsion from the district's vocational education program clearly communicated to him and other students who suffered a similar fate that their career goals were misplaced and that their career aspirations were not worthy of institutional support despite their status as continuation school students. Their dreams were impossible because their achievements were the wrong kind.

\section{ALIENATION THREE: OTHER PEOPLE'S LIVES}

Pinnacle High School's narrow, exacting institutional success frame fostered an academic culture of restless striving and stressful peer-group competition that left students feeling alienated at all achievement levels (Demerath 2009, Nunn 2014, Dhingra 2020). As described in the section on "precarious worth," there was a sense in which achievement was never enough: students continually had to prove to each other and to themselves that they deserved and would eventually gain external validation for their achievements, whether college admission or, later,

prestigious careers. As such, the future was not an "end in view” as Dewey (1923) would describe it, a project that feels obtainable and personally meaningful. Instead, for these students, the future was marked by the uncertainty of sufficient achievement and the need for outside corroboration of worth, making a "resonant" (Rosa 2019) experience of school quite difficult 
indeed. If our concept of "precarious worth" emphasizes the uncertainty with this experience, then the concept of "other people's lives" emphasizes the externality within it. For some students, achievement felt marked and mandated simply by achievement itself rather than as connected to something they felt excited about on their own. This kind of alienation is similar to Seeman's fifth and final form of alienation, which he calls self-estrangement in his classic 1959 article: "the degree of dependence of the given behavior upon anticipated future rewards, that is, upon rewards that lie outside the activity itself" (Seeman 1959: 790).

Pinnacle's exacting success frame and the achievement ideology it engendered were often revealed in school events and traditions. For example, each year in late April Pinnacle held a college sweatshirt day where graduating students came to school wearing a sweatshirt from their college of choice. Sweatshirts from Ivy League, University of California, and other elite four-year colleges and universities were abundant on this day. Graduating seniors congratulated each other and took selfies with their friends in collegiate apparel, laughing and chatting playfully about their decisions and their hopes for freshman year.

The sweatshirt day experience could be alienating for students who had not been admitted to multiple top-ranked colleges. This was certainly true of seniors who were not planning to attend college at all after graduation, but it was also true of accomplished students who were set to enroll at colleges that were not considered at Pinnacle to be "good" schools. Again, this kind of alienation might not be captured in certain studies of schooling; these are students going to college after all, and they are going to schools that in certain contexts or local cultures would be considered worthy achievements. Yet the connection between students' sense of their own lives and their own futures was often regulated by an achievement ideology that set exacting standards about what could be considered successful. In that sense, a student's 
achievements in life became judged by a standard the student sometimes felt powerless to contest, creating situations in which they felt inadequate amongst their peers, or a sense in which they were encouraged to pursue a life not entirely their own.

Diana, a Latina senior and the daughter of Mexican immigrants, had an experience that serves as a case in point. Despite her intention to enroll in college after graduation, she chose not to participate in the sweatshirt day ritual:

\begin{abstract}
AUTHOR ONE: What did you think of college sweatshirt day? Did you wear one?
\end{abstract}

DIANA: Nope! I didn't wear one. I'm going to community college next year, and it's honestly kind of embarrassing sometimes if you're not going to a four-year school. I'm not going to wear something from Valley View Community College when there's people walking around with, like, Stanford stuff on...But I'm proud of me and I know my parents are proud of me, so I don't need anyone at school to accept it.

A subsequent interview with one of her teachers revealed that Diana would be the first in her family to attend college, but this exceptional achievement was overshadowed by her friends and classmates who had parents with graduate degrees and were accepting offers from some of the most highly-ranked colleges and universities in the nation.

Diana's choice to forego participation in the college sweatshirt ritual was her way of coping with the dissonance between her achievements and Pinnacle's institutional success frame. A commitment to an achievement ideology made Diana's impressive achievement feel somewhat empty, and she was alienated by that disconnect between her own project for her future and what she felt obligated to achieve. Diana felt a separation between her pride in what she had already achieved in her life and the sense that the life of a student at Pinnacle should have more prestigious markers. Her sense of accomplishment was blunted by the fact that she perceived others around her to be living more successful lives. 


\section{Even the Greatest Success is Not Enough}

At Pinnacle, the experience of school as a competitive training ground for a lucrative career was also alienating for those who achieved some of the highest grades and test scores. Ryan, the son of Chinese immigrants, and Eugene, whose parents were born in Korea, were enrolled in several AP classes at Pinnacle, including the "hardcore" combination of AP biology and AP chemistry. One day, over coffee at a Starbucks just off campus, both boys talked about Pinnacle's reputation as a demanding academic institution and what it was like to be a student in such as environment:

AUTHOR ONE: Both of you have said that your parents wanted to move to Valley View, and to this neighborhood in particular, so that you would attend Pinnacle for high school. When you were in middle school, did Pinnacle have a certain reputation that you were aware of?

RYAN: It had a reputation as being an amazing school for the academics.

EUGENE: Amazing, but also formidable. Definitely Hardcore.

RYAN: Yeah, hardcore and intimidating.

AUTHOR ONE: So what's it really been like now that you're about to be seniors?

EUGENE: It's definitely a great school for academics, and there are a lot of really good teachers, but it's not really the teachers that make the school what it is. It's mainly the stress level. The stress level is through the roof!

Later in the conversation, they each spoke candidly about their academic aspirations and expectations, as well the feelings of alienation that often accompanied the pursuit of those goals. Importantly, in both of their cases, their ambitions were fueled by a combination of their parents' notions of what a successful career would look like for them, and the routinely lofty achievements of their classmates. There was an acute sense, for both students, that they were living other people's lives, and neither was entirely sure how to separate what they wanted from 
what they felt they were expected to achieve. Perhaps more importantly, both students describe a sense in which the good of academic life is marked not by the enjoyment of subject materials and student comradery, nor even by the successful (even if not always enjoyable) preparation for future college study and careers. Instead, academic experience is marked primarily by academic achievement, and this achievement is nearly always ranked by status and zero-sum competition. As a result, these students felt a separation between their sense of themselves and their sense of their projected lives, exactly the definition of alienation we described in the introduction.

AUTHOR ONE: Is there a lot of competition here between students?

EUGENE: Yeah, a ridiculous amount.

AUTHOR ONE: How does it play out?

EUGENE: A lot of it comes from parents. I got a pretty high score on my Honors Chemistry final last year. I think I got a 95[\%] or a 96[\%] or something, and I was like, "Dad, I got a 96 on my chem final!" I was pretty stoked, but my dad said that he already knew about a girl in the class who had gotten a perfect score, so he told me to work harder and do better next time.

AUTHOR ONE: Is it common for you to hear from your parents about other students here and how well those students are doing?

RYAN: Definitely. Like, there's this kid in our AP chemistry class, and his mom and my mom are friends, and I always have to hear about how high his grades are and how my grades should be just as high.

AUTHOR ONE: Have you explicitly been told by your parents that you need to get straight A's?

EUGENE: Oh, definitely. Very often, my dad actually says, "If you don't end up better than me, to me you're a failure." And I'm like, "Dad, you have a PhD in chemistry - that's pretty amazing." And he's like, "No, you have to be better than me."

AUTHOR ONE: Do you know what he means when he says, "better than me"?

EUGENE: Yeah, he means monetary income and respectability of the job.

RYAN: Which pretty much means doctor, lawyer, engineer. 
EUGENE: Exactly! Doctor, lawyer, or engineer.

\section{AUTHOR ONE: How do you feel about that?}

EUGENE: Chemistry and science have been basically force fed into my mouth, but I don't know if I really like science. I've been told that I like it by other people! But I want to keep my options open.

Ryan and Eugene also spoke about feelings of detachment and disenchantment regarding their schoolwork and their plans for the future:

RYAN: Both my parents are medical doctors, and my mom is also a really heavy chemistry person. Growing up, I've always been taught that to be a successful adult you have to be a doctor or something similar; you have to wear a white coat; you have to be this sort of person. So I really don't see a future of me not wearing a white coat at all. And I don't know if it was forced on me, or if I think I'm fitted for it, but I think I'll be a doctor.

\section{AUTHOR ONE: And Eugene, you're not so sure?}

EUGENE: "I'm not sure at all. [My parents] actually forced me to take an internship in a stem cell laboratory last year that I really did not want to do. They're trying to prepare me for a career that I'm not interested in."

By all numerical measures, Ryan and Eugene were doing extremely well in school; they each held a grade point average above 4.0 , and their standardized test scores were in the $99^{\text {th }}$ percentile nationally. However, despite their clear scholastic achievements, both boys experienced alienation as a direct result of their relentless pursuit of the highest levels of academic success, and specifically regarding the sense in which their future was dictated and decided by someone else. Ryan saw no future for himself in which he was not a doctor wearing a lab coat. Eugene had little interest in the fancy science internship and other opportunities that his parents demanded he participate in. They both felt as if their goals were not their goals - as if their goals were "forced" on them. 
Ryan's and Eugene's experiences were common among Pinnacle's highest achievers. For these students, achievement was almost necessarily empty of the kind of joys traditionally associated with achieving something: the mastery of a skill, the successful completion of a task or challenge. Instead, achievement became empty; it was a status marker, a way of keeping up amidst the mercilessly tightening screws of the achievement ideology. For these students, alienation and achievement were inseparable.

\section{DISCUSSION AND CONCLUSION}

Based on Author One's fieldwork in two high schools in a Southern California suburb, we have described three forms of alienation in schools: precarious worth, impossible dreams, and other people's lives. We argued that these three forms of alienation are maintained by an achievement ideology that makes it difficult for students to separate their achievements from their worth, therefore alienating them by separating their sense of selves and their future projects. In this final section, we describe how our analysis and findings might be relevant for research on schools, alienation, and meritocracy, as well as for broader political discussions of schooling.

First, we hope that our study of alienation can continue a recent trend within the sociology of education to challenge the "stratification paradigm" (Guhin 2021). We hope to have shown that alienation in school is much more than a variable that might explain a lack of achievement. In fact, achievement itself—especially the achievement ideology—might well be itself a cause of alienation. In making this case, we build on other work that seeks to disentangle the study of schools from the study of achievement (Mehta and Davies 2018). While we would need another article to make this case, it is worth using a recent handbook in the sociology of education as one illustration. Published by Springer and edited by Barbara Schneider, The 
Handbook of the Sociology of Education in the $21^{\text {st }}$ Century is an impressive compendium of many of the most important voices in the sociology study of education. And nearly all of the book is about socio-economic inequality, not just how it works but how to fix it. Indeed, as Adam Gamoran, the president of the W.T. Grant Foundation writes in his foreword to the volume, "we need research to identify which programs will be effective in reducing inequality, and that is the point of entry for sociologists of education" (2018: vi).

But what if, following recent prominent arguments (Downey 2020, DeBoer 2020), schools are not the best way to solve inequality? What if, as we hope to have shown here, emphasizing schools as a solution to inequality can inadvertently strengthen a brutal ideology of achievement? This does not mean sociologists of education should give up on their (often implicit) normative commitments to ending inequality. But it might mean that schools are a site to study inequality but not a location through which to solve it. Perhaps more radical redistribution is in order, and schools should simply be studied as schools, still sites of inequality and injustice, no doubt, but no longer weighted with the massive project of solving socioeconomic stratification.

Such a separation of schools as solutions to inequality versus school as sites of inequality might better enable sociologists to examine alienation as a problem in itself, part of a broader opening of the study of schools within sociology and related fields, from a relatively narrow concern about inequality and socio-economic outcomes (Duncan and Murnane 2011) to the much broader examination of all the many ways social life happens at schools (even if these examinations would still be informed by sociological concerns about inequality). Future work could expand on our definition of alienation as necessarily related to selves' projects, linking more explicitly to ongoing debates about aspiration paradoxes (Nielsen 2015, Frye 2012) and 
educational transitions (Goldrick-Rab and Pfeffer 2009). There is also important room for explicitly looking at alienation as it relates to marginalized identities as well as focusing more solidly on the role of specific practices in alienating students, including discipline (Ramey 2015), counseling (Stanton-Salazar 2001), and pedagogy itself (Marks 2000).

It is worth acknowledging that students like Patrick and Eugene (who we discuss in our third empirical section) are likely headed for very different - and financially superior - outcomes than Dominique and Miguel, but that they are still alienated despite their success and lofty school and career trajectories. A focus on schools-as-solutions to inequality might miss that alienation entirely. We want to emphasize how the stakes of socio-economic inequality are so high that thinking of schools as solutions can be deeply alienating, certainly for those who "can't make it" but even for those who can and do. Finally, it is worth reiterating a point in our theory section that schools are not necessarily alienating places. This is even the case in schools like Pinnacle, which, despite the stress, might find students for whom a good "fit" causes no explicit sense of alienation (Bourdieu 1998). Yet schools often are alienating, and despite previous sociological efforts, achievement might well be more the cause than the solution. 


\section{Works Cited}

Aberbach, Joel D. 1969. "Alienation and political behavior." American Political Science Review 63(1): 86-99.

Abrutyn, Seth, and Anna S. Mueller. 2014. "The Socioemotional Foundations of Suicide: A Microsociological View of Durkheim's Suicide." Sociological Theory 32(4): 327-51

Acevedo, Gabriel. 2005. Turning anomie on its head: Fatalism as Durkheim's concealed and multidimensional alienation theory. Sociological Theory 23(1): 75-85.

Au, Wayne, and Michael W. Apple. 2009. "Rethinking reproduction: Neo-Marxism in critical education theory" pp. 83-95 The Routledge International Handbook of Critical Education. Ed. Michael W Apple, Wayne Au, and Luis Armando Gandin. Routledge.

Baker, David. 2020. The schooled society. Stanford: Stanford University Press.

Berger, Peter L and Thomas Luckmann. 1967. The social construction of reality. Anchor Books.

Bourdieu, Pierre, and Jean-Claude Passeron. 2000. Reproduction in Education, Society and Culture. $2^{\text {nd }}$ Ed. Tr. Richard Nice. Thousand Oaks: Sage.

Bourdieu, Pierre. 1991. Language and symbolic power. Cambridge, MA: Harvard University Press. Tr. Gino Raymond and Matthew Adamson. Ed. John B. Thompson.

Bourdieu, Pierre. 2000. Pascalian meditations. Tr. Richard Nice. Stanford: Stanford University Press.

Bourdieu, Pierre. 1998. The state nobility: Elite schools in the field of power. Tr. Lauretta C. Clough. Stanford: Stanford University Press.

Bowles, Samuel, and Herbert Gintis. 1976. Schooling in capitalist America: Educational reform and the contradictions of economic life. New York: Basic Books.

Carter, Prudence L. 2005. Keepin' It Real: School Success Beyond Black and White. New York: Oxford University Press.

Carter, Prudence L. 2003. “'Black' Cultural Capital, Status Positioning, and Schooling Conflicts for Low-Income African American Youth. Social Problems 50 (1) 136-155.

Carter, Prudence and Keven Welner, eds. 2013. Closing the Opportunity Gap: What American Must Do to Give Every Child in America an Even Chance. New York: Oxford University Press.

Castilla, Emilio J. and Stephen Benard. 2010. "The Paradox of Meritocracy in Organizations." Administrative Science Quarterly. 55(4): 543-676. 
Comaroff, Jean, and John L. Comaroff. 2008. Of revelation and revolution, volume 1:

Christianity, colonialism, and consciousness in South Africa. Chicago: University of Chicago Press.

Conchas, Gilberto Q. 2006. The Color of Success: Race and High-Achieving Urban Youth. New York: Teachers College Press.

Conchas, Gilberto Q. and James Diego Vigil. 2012. Streetsmart Schoolsmart: Urban Poverty and the Education of Adolescent Boys. New York: Teachers College.

Cottom, Tressie McMillan. 2017. Lower Ed: The Troubling Rise of For-Profit Colleges in the New Economy. New York: The New Press.

Dean, Dwight G. 1961. "Alienation: Its meaning and measurement." American Sociological Review 26(5): 753-758.

Demerath, Peter. 2009. Producing Success. Chicago: University of Chicago Press.

Dewey, John. 1997. Democracy and Education. New York: Free Press.

Dewey, John. 1923. Democracy and education: An introduction to the philosophy of education. New York: Macmillan.

Dhingra, Pawan. 2020. Hyper education: Why good schools, good grades, and good behavior are not enough. New York: NYU Press.

Downey, Douglas B. 2020. How schools really matter: Why our assumption about schools and inequality is mostly wrong. Chicago: University of Chicago Press.

Drake, Sean J. 2017. "Academic Segregation and the Institutional Success Frame: Unequal Schooling and Racial Disparity in an Integrated, Affluent Community." Journal of Ethnic and Migration Studies 43 (14) 2423-2439.

Duncan, Greg J. and Richard J. Murnane, eds. 2011. Whither Opportunity?: Rising Inequality, Schools, and Children's Life Chances. New York: Russell Sage Foundation.

Duneier, Mitchell. 2011. "How Not to Lie With Ethnography." Sociological Methodology 41 (1): $1-11$.

Durkheim, Emile. 2006. On Suicide. Tr. Robin Buss. New York: Penguin Classics

Erikson, Kai. 1986. "On work and alienation." American Sociological Review 51(1): 1-8.

Felski, Rita. 2020. "Resonance and education." On Education. Journal for Research and Debate 3(9): 1-4. 
Fischer, Claude S. 1973. On urban alienations and anomie: Powerlessness and social isolation. American Sociological Review 38(3): 311-326.

Frye, Margaret. 2012. "Bright futures in Malawi’s new dawn: Educational aspirations as assertions of identity." American Journal of Sociology 117(6): 1565-1624.

Gellner, Ernest. 2008. Nations and Nationalism. Ithaca, NY: Cornell University Press.

Giroux, Henry. 1983. "Theories of reproduction and resistance in the new sociology of education: A critical analysis." Harvard educational review 53(3): 257-293.

Goldrick-Rab, Sara, and Fabian T. Pfeffer. 2009. "Beyond access: Explaining socioeconomic differences in college transfer." Sociology of Education 82(2): 101-125.

Guhin, Jeffrey, Jessica McCrory Calarco, and Cynthia Miller-Idriss. 2021. "Whatever Happened to Socialization?." Annual Review of Sociology 47: 109-129.

Guhin, Jeffrey. 2021. "Why Study Schools?” In S. Abrutyn, O. Lizardo (eds.), Handbook of Classical Sociological Theory. Pp. 381-397.

Hascher, Tina, and Andreas Hadjar. 2018. "School alienation-Theoretical approaches and educational research." Educational Research 60(2): 171-188.

Heidegger, Martin. 2010. Being and Time. Tr. Joan Stambaugh. SUNY Press.

hooks, bell. 2003. Teaching community: A pedagogy of hope. Psychology Press.

Honneth, Axel. 2008. Reification: A new look at an old idea. Oxford University Press.

Howard, Tyrone C. 2008. "Who Really Cares? The Disenfranchisement of African American Males in PreK-12 Schools." Teachers College Record 110 (5): 954-985.

Howard, Tyrone C. 2013. "How Does it Feel to be a Problem? Black Male Students, Schools, and Learning in Enhancing the Knowledge Base to Disrupt Deficit Frameworks." Review of Research in Education 37 (1): 54-86.

Jaeggi, Rahel. 2014. Alienation. Tr. Frederick Neuhouser and Alan E. Smith. Columbia University Press.

Kliebard, Herbert M. 2004. The struggle for the American curriculum, 1893-1958. New York: Psychology Press.

Kohn, Melvin L. 1976. "Occupational structure and alienation." American Journal of Sociology 82(1): 111-130. 
Labaree, David F. 2012. Someone has to fail: The zero-sum game of public schooling.

Cambridge, MA: Harvard University Press.

Ladson-Billings, Gloria. 1995. "Toward a theory of culturally relevant pedagogy." American Educational Research Journal 32(3): 465-491.

Ladson-Billings, Gloria. 2006. "From the achievement gap to the education debt: Understanding achievement in US schools." Educational researcher 35(7): 3-12.

Lampert, Khen. 2013. Meritocratic education and social worthlessness. New York: Palgrave McMillan.

Lazenby, Hugh. 2016. "What Is Equality of Opportunity in Education?" Theory and Research in Education 14(1): 65-76.

Lewis, Amanda E. 2003. Race in the Schoolyard: Negotiating the Color Line in Classrooms and Communities. New Brunswick, NJ: Rutgers University Press.

Love, Bettina L. 2019. We want to do more than survive: Abolitionist teaching and the pursuit of educational freedom. Beacon Press.

Lukes, Steven. 2011. "In defense of false consciousness." University of Chicago Legal Forum. p. 19-28.

Lukes, Stephen. 1967. Alienation and Anomie. Pp. 134-56 in Philosophy, Politics, and Society, edited by P. Laslett and W. G. Runciman. Oxford, UK: Basil Blackwell.

Marks, Helen M. 2000. "Student engagement in instructional activity: Patterns in the elementary, middle, and high school years." American Educational Research Journal 37(1): 153-184.

Mau, Rosalind Y. 1992. "The validity and devolution of a concept: Student alienation." Adolescence. 27(107): 731-741.

McNamee, Stephen J., and Robert K. Miller. 2009. The meritocracy myth. Lanham, MD: Rowman \& Littlefield.

Mead, George Herbert. 2002. The philosophy of the present. New York: Prometheus Press.

Mehta, Jal, and Scott Davies. 2018. "Education in a New Society: Renewing the Sociology of Education" in Education in a New Society: Renewing the Sociology of Education. Ed. Jal Mehta and Scott Davies. University of Chicago Press.

Mische, Ann. 2014. "Measuring futures in action: Projective grammars in the Rio+ 20 debates." Theory and Society 43(3-4): 437-464. 
Morinaj, Julia, and Tina Hascher. 2019. "School alienation and student well-being: A crosslagged longitudinal analysis." European Journal of Psychology of Education 34(2): 273 294.

Newmann, Fred. "Reducing student alienation in high schools: Implications of theory." 1981. Harvard Educational Review 51(4): 546-564.

Newman, Benjamin J., Christopher D. Johnston, and Patrick L. Lown. 2015. "False consciousness or class awareness? Local income inequality, personal economic position, and belief in American meritocracy." American Journal of Political Science 59(2): 326340.

Nielsen, Kelly. 2015. "'Fake It'til You Make It'” Why Community College Students' Aspirations "Hold Steady'." Sociology of Education 88(4): 265-283.

Noguera, Pedro A. 2008. The Trouble with Black Boys...And Other Reflections on Race, Equity, and the Future of Public Education. San Francisco, CA: John Wiley \& Sons.

Nunn, Lisa M. 2014. Defining student success. New Brunswick: Rutgers University Press.

Ollman, Bertell. 1976. Alienation: Marx's conception of man in capitalist society. Cambridge: Cambridge University Press.

Purser, Gretchen, and Brian Hennigan. 2017. "“Work as Unto the Lord': Enhancing Employability in an Evangelical Job-Readiness Program.” Qualitative Sociology 40(1): 111-133.

Ramey, David M. 2015. "The social structure of criminalized and medicalized school discipline." Sociology of Education 88(3): 181-201.

Ricoeur, Paul. 1977. Freud and philosophy: An essay on interpretation. New Haven: Yale University Press.

Rinaldo, Rachel, and Jeffrey Guhin. 2019. "How and why interviews work: Ethnographic interviews and meso-level public culture." Sociological Methods \& Research. 0049124119882471.

Rios, Victor M. 2011. Punished: Policing the Lives of Black and Latino Boys. New York, NY: New York University Press.

Rios, Victor M. 2017. Human Targets: Schools, Police, and the Criminalization of Latino Youth. Chicago, IL: University of Chicago Press.

Rosa, Hartmut. 2019. Resonance: A sociology of our relationship to the world. Medford, MA: Polity Press. 
Rosenbaum, James E. 2001. Beyond college for all: Career paths for the forgotten half. New York: Russell Sage Foundation.

Sandel, Michael J. 2020. The Tyranny of Merit. New York: Penguin.

Schacht, Richard. 1970. Alienation. New York: Psychology Press.

Sciulli, David. 1984. Talcott Parsons's analytical critique of Marxism's concept of alienation. American Journal of Sociology 90(3): 514-540

Seeman, Melvin. 1959. "On the meaning of alienation." American Sociological Review 24(6): 783-791.

Skotnicki, Tad, and Kelly Nielsen. 2021. "Toward a theory of alienation: futurelessness in financial capitalism." Theory and Society 50: 837-865.

Snow, David A., Louis A. Zurcher, and Gideon Sjoberg. 1982. "Interviewing by Comment: An Adjunct to the Direct Question." Qualitative Sociology 5 (4): 285-311.

Stanton-Salazar, Ricardo D. 2001. Manufacturing Hope and Despair: The School and Kin Support Networks of US-Mexican Youth. New York, NY: Teachers College Press.

Steffes, Tracy L. 2011. School, Society, and State. Chicago: University of Chicago Press.

Taines, Cynthia. 2012. "Intervening in Alienation: The Outcomes For Urban Youth of Participation in School Activism." American Educational Research Journal 49 (1): 53 86.

Tavory, Iddo, and Nina Eliasoph. 2013. "Coordinating futures: Toward a theory of anticipation." American Journal of Sociology. 118(4): 908-942.

TenHouten, Warren D. 2017. Alienation and affect. London: Routledge.

Warikoo, Natasha and Prudence L. Carter. 2009. "Cultural Explanation for Racial and Ethnic Stratification in Academic Achievement: A Call For a New and Improved Theory." Review of Educational Research 79 (1) 366-394.

Weber, Eugen. 1976. Peasants into Frenchmen: the modernization of rural France, 1870-1914. Stanford: Stanford University Press.

Weber, Max. 2001. The Protestant Ethic and the Spirit of Capitalism. Tr. Stephen Kalberg. New York: Routledge.

Willis, Paul. 1977. Learning to labour: How working class kids get working class jobs. New York: Columbia University Press. 
Withy, Katherine. 2014. "Situation and limitation: Making sense of Heidegger on thrownness." European Journal of Philosophy 22(1): 61-81.

Yuill, Chris. 2011. "Forgetting and remembering alienation theory." History of the Human Sciences 24(2): 103-119.

Young, Michael. 2017. The rise of the meritocracy. New York: Routledge.

Zaloom, Caitlin. 2019. Indebted: How families make college work at any cost. Princeton: Princeton University Press. 